\title{
SER PROFESSOR DE HISTÓRIA HOJE: ALGUMAS REFLEXÕES
}

\author{
José Petrúcio de Farias Júnior
}

RESUMO: A proposta desse artigo é fomentar algumas reflexões sobre a prática de ensino de História na Educação Básica e os principais desafios do professor de História hoje. Reconhecemos que ainda há certo distanciamento entre as reflexões sobre o ensino de História, veiculadas no meio acadêmico, e as práticas de ensino de História, vivenciadas em sala de aula na Educação Básica, situação que representa um grande desafio aos recém-formados.

Palavras-chave: Ensino de História; Metodologia de ensino; Formação de professor.

ABSTRACT: The proposal of this article is to encourage some thoughts on the practice of history teaching in basic education and the main challenges of the history teacher today. We recognize that there is still a certain gap between reflections on the teaching of history, conveyed in academia, and history teaching practices, experienced in class in basic education, a situation that represents a major challenge to new graduates.

Keywords: Teaching of History; Teaching methodology; Teacher training.

As graduações voltadas à formação de professores têm sido fomentadas em nosso país, tanto na modalidade presencial quanto a distância. Diante disso, podemos notar um significativo aumento de oferta de vagas, sobretudo para os cursos de licenciatura em História no ensino superior, nos últimos anos. Questionamo-nos, no entanto, em que medida os cursos de licenciatura em História apresentam propostas curriculares voltadas à formação do professor, isto é, afinadas a propostas da educação básica no que diz respeito à formação de cidadãos bem como ao papel da disciplina no conjunto de saberes adquiridos nesta etapa escolar.

A despeito das particularidades que cercam ambas as modalidades de ensino, reconhecemos que as licenciaturas em História geralmente se esforçam por uma formação acadêmica que ofereça aos graduandos pontos de

\footnotetext{
"Docente da Universidade Federal do Piauí (UFPI) - Campus de Picos. Doutor em História pela Universidade Estadual Paulista "Júlio de Mesquita Filho" (Unesp) - Campus de Franca. E-mail: petruciojr@terra.com.br
} 
reflexão sobre a natureza do conhecimento histórico acadêmico e seus limites, no entanto, observa-se ainda que as disciplinas nucleares ou obrigatórias dos cursos de licenciatura, tais como História Antiga, Medieval, Moderna, Contemporânea, História do Brasil, da América, entre outras, encontram-se geralmente dissociadas das questões atinentes à prática de ensino ou metodologias de ensino de História, as quais constituem disciplinas à parte, ou seja, não estão necessariamente integradas às disciplinas nucleares da licenciatura.

Adicionado a isso, observa-se que as disciplinas pedagógicas são em geral ministradas por docentes que pertencem a outros departamentos, como educação, e que não necessariamente estabelecem um diálogo estreito não só com os docentes do colegiado de História, mas também com a construção do conhecimento histórico, aspectos indispensáveis, a nosso ver, para a formação do professor de História e para a compreensão da especificidade do saber histórico escolar.

Com o processo de expansão das universidades públicas federais, por exemplo, tem se observado a instalação de campi universitários pelo interior dos estados brasileiros dotados de cursos de formação de professores, a saber: história, letras, pedagogia, geografia, ciências biológicas, entre outras, no interior dos quais se reproduz o modelo segmentado, em que atuam nos cursos de História, pedagogos e historiadores sem que haja projetos de ensino em comum entre tais especialistas.

Os pedagogos são, na grande maioria dos casos, solicitados a atuar em todos os cursos de licenciatura onde estão lotados e, como resultado dessa prática, elaboram planos de ensino que pouco ou nada se relacionam com questões atinentes à natureza do conhecimento histórico ou apenas tangenciam uma questão fundamental à formação do professor de História: a construção do conhecimento histórico escolar, por isso, ainda que os projetos pedagógicos manifestem certo diálogo entre as disciplinas bem como sinalizem a interdisciplinaridade, os pedagogos que atuam nos cursos de licenciatura em História seguem com planos de ensino que comumente negligenciam temas como 'didática da História' (que se diferencia sobremaneira da didática geral) e 'educação histórica'. 
Essa questão, todavia, é polêmica e divide opiniões, pois os cursos de pós-graduação que atuam na área de ensino de História no Brasil estão predominantemente vinculados aos departamentos de Educação e não de História. Lembramos, todavia, que, tanto a integração da carga horária das disciplinas nucleares a práticas de ensino, quanto ao aprofundamento de temas de ensino de História em que pedagogos e historiadores estejam em diálogo e atuem colaborativamente, na graduação, são questões urgentes à formação inicial de professores de História.

No âmbito da metodologia do ensino de História, discute-se com certa frequência, no meio acadêmico, os resultados do ensino de História alicerçados na chamada "História tradicional" de cunho positivista, que se concentrava basicamente em uma narrativa focada em aspectos políticos (grandes realizações e grandes heróis da nação). Tratava-se, como muitos pesquisadores já registraram, de uma História externa ao universo simbólico dos alunos, ou seja, da qual eles não se sentiam participantes. Era comum que os docentes ouvissem tais indagações: Por que estudar esses personagens históricos, uma vez que estão todos mortos? ou $\mathrm{O}$ que eu tenho a ver com isso? Muitos diziam ironicamente "não conheço estas pessoas, logo isto não me interessa". Paulo Miceli, ao olhar para este cenário, declara que

[...] enquanto o mundo acontece, a História - conhecimento compulsório para o aluno - parecia voltar-se para trás, sustentando-se numa sucessão de mortos-famosos, acontecimentos distantes e sem relação com a vida do estudante (MICELI, 2001, p. 44)

Enfim, a História se resumia a uma disciplina distante das vivências dos alunos e objetivava transmitir informações - marcadas por uma intencionalidade político-cultural - para que fossem memorizadas e, posteriormente, reproduzidas em exames como critério para aprovação na disciplina. Os altos índices de rejeição à disciplina e os movimentos sociais das décadas de 70, 80 e 90, no contexto do processo de redemocratização brasileira, colaboraram para reformulação do ensino de História e para 
conscientização de que tanto as universidades quanto as escolas são espaços de produção do conhecimento histórico.

No interior desse contexto de mudanças quanto à concepção de ensino de História, Paulo Miceli nos propõe alguns caminhos que devem, ao menos em parte, nortear o professor de História.

\begin{abstract}
Uma das primeiras regras indicadas ao bom desempenho da função docente é aquela que recomenda a valorização da experiência cotidiana dos alunos. Sobre isso, pode-se perguntar quais experiências cotidianas do aluno podem servir ao professor de História, para que ele cumpra seu papel de formador? Mais ainda como considerar a aplicação dessa vivência para fortalecer as bases da cidadania, desde os anos iniciais de estudo? (MICELI, 2011, p. 38, grifo nosso)
\end{abstract}

Defende-se, dado o exposto, que, para despertar o interesse do aluno, é aconselhável que os conteúdos históricos sejam introduzidos a partir de questões ou situações-problema que estejam relacionados às experiências cotidianas dos alunos ou questões que contemporaneamente nos inquietam ou envolvem.

As situações-problema podem sensibilizar os estudantes a pensar sobre o tema proposto, tendo em vista seus conhecimentos prévios, a atribuir sentido àquilo que estudam em sala de aula e a aprofundar seus pontos de vista, além de atuar como fio condutor para o desenvolvimento da situação de aprendizagem. No entanto é recomendável que o professor evite digressões, ou seja, as indagações propostas pelo docente devem estar estreitamente vinculadas aos objetivos da situação de aprendizagem proposta, de tal forma que, ao final das atividades, os alunos consigam responder, pelo menos, parte das questões levantadas inicialmente.

Essa metodologia permite que os discentes entendam com mais propriedade a sociedade na qual eles vivem e reforça sua condição de agentes históricos, uma vez que passam a refletir sobre em que medida experiências e comportamentos humanos do passado que se refletem, de alguma maneira, no presente. 
Isso posto, fica claro que estudar o passado consiste em buscar compreender o nosso próprio mundo e um tema bastante recorrente no ensino de História versa sobre a construção de identidades culturais motivadas por questões, tais como: o que faz um brasileiro 'brasileiro' ou um católico 'católico', um umbandista 'umbandista', um espírita 'espírita', enfim, como as pessoas constroem seus espaços de vivência, suas visões de mundo, seus princípios e valores sociais são aspectos da vida cotidiana que impulsionam, em grande medida, o ensino de História.

Sob essa ótica, o estudo do passado permite aprofundar e problematizar nossas experiências cotidianas, amplia a compreensão das experiências culturais a que estamos submetidos e, principalmente, contribui para desnaturalizar formas de agir e pensar, já que elas passam a ser vistas como construção humana em constante processo de mudança ou reformulação.

É preciso considerar que a maioria das pessoas manifesta uma postura a-histórica e até mesmo anti-histórica acerca do meio social na qual vivem e tal postura delimita suas crenças, ideias e percepções sobre a vida e sobre 0 'outro'. Essas pessoas tendem a pensar que o mundo em que vivemos foi do mesmo jeito que vemos agora; acreditam que nossas organizações familiares, religiosas, políticas, sociais são assim desde sempre e não percebem que nossa própria situação de seres situados em um tempo e em um lugar cria uma espécie de 'ilusão de ótica' em que nossas convicções, nossas estruturas familiares, princípios e valores religiosos parecem ser dados naturais e não criações humanas que têm a sua história.

Quando naturalizamos formas de pensar e agir com as quais estamos habituados, tendemos a universalizar nossa visão de mundo e a crer que tal visão se aplica a todas as outras sociedades. Isso quer dizer que a maioria das pessoas não questionam seus próprios valores e princípios e, por isso, reproduzem preconceitos sem nunca ter pensado sobre eles ou perpetuam ideias sem que tivessem observado suas limitações (ou inadequações).

Sendo assim, uma das propostas centrais do ensino de História na Educação Básica consiste em indagar o presente, ou seja, problematizar as situações sociais nas quais estamos enredados e se posicionar de maneira menos ingênua na sociedade em que vivemos. Vera Cabana Andrade reitera a 
necessidade de tais reflexões em Ensino de História: sujeitos, saberes e práticas:

\begin{abstract}
Ensinar História hoje - história como construção, diálogo passado/presente, problematização de questões oriundas do presente, mas que se apresentam em diferentes tempos históricos - [...] encerra uma questão básica: como ensinar os alunos a pensar historicamente? Em outras palavras: como direcionar as ações pedagógicas no sentido do desenvolvimento do pensamento histórico dos alunos? Sem dúvida, tarefa das mais complexas, considerando que o exercício mental de pensar historicamente não é uma capacidade inata, ou mesmo dada, mas, sim, uma forma de raciocinar adquirida através da prática sistemática e específica de operações cognitivas e afetivas. Tarefas das mais difíceis para o professor formado na história tradicional - visão evolucionista do tempo linear e da narrativa cronológica, em que o antes explica o depois - e que não foi "educado", aqui entendido como sinônimo de treinado e/ou preparado para perceber a dimensão temporal das ações humanas manifestas no presente [...] (2007, p. 234)
\end{abstract}

Dado o exposto, destacar a importância e o grau de pertencimento dos estudantes na historicidade das experiências humanas é um caminho para aproximá-los dos conteúdos abordados na disciplina e, com isso, despertar o interesse pelos temas sugeridos pelo docente. Como afirma Schmidt (2010, p. 57) ensinar História passa a ser (...) dar condições para que o aluno possa participar do processo do fazer, do construir a História.

Adicionado a isso, é indispensável mostrar ao aluno que a História não é constituída de fatos prontos e acabados, do ponto de vista da interpretação. Novas fontes históricas e novas abordagens sobre fontes históricas já analisadas podem modificar a forma como olhamos para o passado e tais descobertas ou possibilidades alternativas de leitura do passado reforçam o fato de que lemos as fontes históricas a partir de indagações e interesses do nosso tempo.

Nesse sentido, o professor pode ensinar os estudantes a adquirir ferramentas necessárias à construção de seus próprios conhecimentos. Assim, o "saber-fazer" torna-se uma prerrogativa para produção autônoma de 
conhecimentos históricos. Sob essa perspectiva, o aluno é convidado a respeitar e valorizar os diferentes pontos de vista sobre um acontecimento histórico e reconhecer-se como agente desse processo de reflexão, uma vez que ele também pode se posicionar, tendo em vista seus conhecimentos prévios.

Sob essa ótica, a sala de aula deixa de ser o espaço em que apenas se transmite informações e torna-se um espaço onde professores e estudantes constroem sentidos, dito isto, as aulas de História também se tornam um espaço de criação, norteado, é claro, por procedimentos singulares de investigação. Em relação a essa estratégia de ensino, Schmidt explica que:

[...] o que se procura é algo diferente, ou seja, a realização na sala de aula da própria atividade do historiador e do fazer pedagógico. Assim, o objetivo é fazer com que o conhecimento histórico seja ensinado de tal forma que dê ao aluno condições de participar do processo do fazer, do construir a História. Que o aluno possa entender que a apropriação do conhecimento é uma atividade em que se retorna ao próprio processo de elaboração do conhecimento (SCHMIDT, 2010, p. 59)

A partir do momento em que o aluno se conscientiza de que a História é principalmente uma fabricação pessoal e intertextual, evita-se uma abordagem reducionista, ancorada em uma única análise causal como elemento explicativo para o acontecimento histórico.

Tal prática pedagógica requer que o professor saiba selecionar e organizar diferentes fontes históricas, ou seja, diferentes abordagens ou pontos de vista sobre um determinado aspecto do passado com a finalidade de mostrar aos estudantes a complexidade dos acontecimentos. É importante fazê-los entender que numerosas relações causais e motivações diferentes interferem na atuação do sujeito histórico. Dito isto, ilustramos nossas reflexões auxiliados, mais uma vez, por Miceli

[...] fazer História pode começar pelo que seria a inversão de um quebra-cabeças: o acontecimento pronto e acabado, que sempre compõe uma imagem que ambiciona abranger a totalidade, deve ser decomposto para denunciar aos 
espectadores o arbítrio de sua construção, como se alguém mostrasse à plateia os fios invisíveis que sustentam os truques do ilusionista - tão sobrenatural quanto qualquer um de nós (MICELI, 2011, p. 45)

Fica claro que se deve preocupar menos com a determinação finalista causa-acontecimento-consequência e mais com a busca de uma explicação multifacetada e plural do passado que revele mudanças e permanências ou continuidades e descontinuidades das experiências humanas (SCHMIDT, 2010, p.60). Em consonância com essa prática pedagógica, Fonseca assevera que:

O professor formador, ao diversificar as fontes e dinamizar as práticas, democratiza o acesso ao saber, possibilita o confronto e o debate de diferentes visões, estimula a incorporação e o estudo da complexidade da cultura e da história [...] (FONSECA, 2009, p. 150)

Com isso, Fonseca reitera a necessidade de o professor de História adotar uma postura reflexiva não só sobre os próprios saberes específicos de sua área, mas também sobre suas convicções e pontos de vista acerca desses saberes. Essa postura evita, por parte do professor de História, o cultivo de atitudes e preconceitos que desvalorizam determinados grupos sociais, étnicos e religiosos.

Sabe-se que não é possível ensinar História de um modo neutro, ou seja, é impossível trabalhar com temas históricos com a mesma isenção do professor que ensina equação ou concordância verbal, como reitera Miceli, reconhecemos que ensinar História também significa comprometer-se com visões de mundo, expectativas sobre a vida em que os chamados atentados terroristas, práticas de corrupção, formas de exploração e prostituição humanas, diversos tipos de violência e preconceitos precisam ser tratados de modo crítico e à luz de investigações que consideram as experiências humanas no tempo (2011, p. 39).

Para Fonseca (2010, p. 151) isso requer assumir o ofício de professor como uma forma de luta política e cultural, no interior da qual o entrecruzamento de diferentes fronteiras, no âmbito da construção de 
identidades, sempre fluidas e estabelecidas por intermédio de relações de poder entre diferentes grupos que compõem a sociedade, tornam-se a tônica para relação ensino-aprendizagem.

Então, consciente de que, ao ensinar História, o discurso do docente é imbuído de uma orientação político-cultural que deriva, pelo menos em parte, de suas influências e experiências cotidianas, o ensino de História deixa de ser concebido como um processo unilateral em que o discurso do professor se reveste do estatuto de verdade científica e se dirige ao discente a fim de que este o memorize. Ao contrário, entende-se que a construção do conhecimento histórico escolar deve partir de uma atividade interativa e colaborativa pautada na análise de fontes históricas e técnicas de pesquisa.

Então, o principal desafio do professor de História hoje consiste em elaborar situações de aprendizagem que contribuam para a construção autônoma do conhecimento histórico. Para isso, convém que o docente instigue os alunos a produzir conhecimentos a partir das fontes históricas, 0 que requer a participação ativa e constante dos estudantes em sala de aula. Essa metodologia de ensino mostra aos alunos que o conhecimento histórico não é algo pronto, acabado, uma verdade científica, pelo contrário, é passível de revisão, reformulação e percebido por sujeitos históricos de maneira diferente.

Visto por esse ângulo, reconhece-se que o professor de História hoje, mais do que um profissional do ensino, torna-se um profissional da aprendizagem, isto é, habilitado a organizar situações de aprendizagem que conduzam os estudantes a se posicionar de maneira autônoma e propositiva.

Marco Silva (2001), em Sala de aula interativa defende que, a cooperação entre os discentes em sala de aula possibilita que o conhecimento seja construído de maneira colaborativa, isto é, a partir da experiência ou pontos de vista de cada um. Nesse sentido, defendemos que os diferentes olhares ou formas de compreender determinado tema seja a maior riqueza das aulas dialogadas, pois, por intermédio de atividades interativas, cada um tem a oportunidade de manifestar seu ponto de vista e, com isso, modificar a maneira de pensar do 'outro' ou simplesmente aludir a elementos que, por outros, foram negligenciados no processo de análise documental. 
No interior dessa prática de ensino, é importante destacar que os discentes se veem como protagonistas no processo de aprendizagem e tornam-se, por extensão, agentes em constante estado de transformação.

Para que as diferentes opiniões sejam fomentadas e respeitadas em sala de aula, é oportuno que o docente valorize a participação discente e, a nosso ver, um dos meios para isso consiste em, ao final da aula ou da situação de aprendizagem, sintetizar os pontos de vista apresentados pelos estudantes com a finalidade de mostrar os caminhos pelos quais percorreram no transcorrer da aula, tendo em vista as múltiplas referências do alunado. Além disso, com base em suas intervenções, podem-se propor novos questionamentos que visam ao aprofundamento dos posicionamentos veiculados.

Com essa prática pedagógica, pretende-se que os discentes reflitam sobre suas contribuições, tendo em vista a aquisição de uma postura críticoreflexiva e relacionem os conteúdos disciplinares às situações de vida em que estão inseridos. Ao professor de História, cabe a identificação e valorização das competências e habilidades dos discentes bem como a proposição de novos desafios.

De modo abrangente, as aulas dialogadas e as atividades coletivas tencionam que os discentes se sensibilizem com 0 assunto estudado $e$ amadureçam suas formas de pensar. Nesse sentido, não se pode deixar de mencionar a relevância da ação mediadora do professor, sobretudo de História, nos processos de ensino-aprendizagem.

Torna-se indispensável que o docente desenvolva estratégias comunicativas motivadoras que possibilitem a construção de laços afetivos entre todos os membros da 'comunidade aprendente', a saber: professor/aluno e aluno/aluno.

Em síntese, enfatizamos a importância de o professor viabilizar um ambiente educacional interativo, marcado pelo respeito entre todos os agentes envolvidos no processo educativo e, principalmente, democrático, no interior do qual o discente tem a liberdade de se exprimir e refletir não só sobre si mesmo, mas também sobre suas experiências cotidianas. 
Com isso, o professor se compromete em oferecer uma formação escolar desprovida de condicionamentos, coerções e memorização de conteúdos. A avaliação e a qualidade de ensino, estão, a nosso ver, associadas à capacidade de criação ou cocriação bem como ressignificação de informações pelos discentes, prática que os torna autônomos e mais conscientes sobre o seu papel na sociedade.

Com base nessa concepção de ensino de História que se ajusta à concepção de educação como um processo aberto, contínuo, construtivo e permanente, as práticas avaliativas podem incorporar um caráter diagnóstico, investigativo e processual, como nos esclarece Fonseca:

\begin{abstract}
Elas devem favorecer a identificação dos problemas, dos níveis de desenvolvimento individual e coletivo, dos significados e práticas, das estratégias, dos modos de construção das aprendizagens [...] devem guardar coerência com os objetivos, os temas, as metodologias e possibilitar o enriquecimento do trabalho pedagógico dos professores e a aprendizagem dos alunos (FONSECA, 2009, p. 155)
\end{abstract}

Para além dessas discussões de caráter teórico-metodológico sobre o ensino de História, Miceli (2011) adiciona indagações fundamentais ao professor de História, as quais estão relacionadas à sua área específica de formação, a saber: é possível levar a aprender sem ensinar? Isto é, o professor deve ter clareza quanto à necessidade de aplicação de conceitos que compõem o vocabulário elementar da disciplina que ministra ${ }^{1}$, tal como previsto pelas propostas curriculares ou programas oficiais de ensino.

Em síntese, imaginamos que "ser professor de História hoje", tendo em vista um contexto histórico marcado pelo amplo acesso à educação básica oferecida pelo Estado bem como uma renovação do ensino de História que derivou da mobilização de historiadores em defesa do respeito à diferença $\mathrm{e}$ aos princípios de cidadania e dignidade humana, assegurados pela Constituição de 1988, requer a adoção de práticas pedagógicas que valorizam

\footnotetext{
${ }^{1}$ Para saber mais, ler Bezerra (2003), o qual discute a aplicação dos chamados conceitos estruturadores da disciplina, tais como: história, processo histórico, tempo (temporalidades históricas), sujeito histórico, cultura, historicidade dos conceitos e cidadania.
} 
o aluno e suas experiências cotidianas; também requer o estímulo à oralidade e à produção do conhecimento histórico a partir da análise de fontes históricas diversificadas (textos, mapas, fotografias, documentários, gráficos, músicas, entre outros), e, por fim, requer o domínio de conteúdos e conceitos estruturadores da disciplina para elaboração de situações de aprendizagem que visam ao desenvolvimento de habilidades e competências específicas e, sobretudo, ter consciência de que o conhecimento histórico é um meio para compreender a nós mesmos e o mundo em vivemos.

\section{REFERÊNCIAS BIBLIOGRÁFICAS}

ANDRADE, V. C. Repensando o documento histórico e a sua utilização no ensino. In: MONTEIRO,A. M; GASPARELLO, A. M; MAGALHÃES, M. S. Ensino de História: sujeitos, saberes e práticas. Rio de Janeiro: Mauad X, 2007.

BEZERRA, H. G. Ensino de História: conteúdos e conceitos básicos. In: KARNAL, L. (Org.) História na sala de aula: conceitos, práticas e propostas. São Paulo: Contexto, 2003.

MICELI, P. Uma pedagogia da História? In: PINSKY,J (Org.) 0 ensino de História e a criação do fato. São Paulo: Contexto, 2011.

FONSECA, S. G. A. constituição de saberes pedagógicos na formação inicial do professor para o ensino de História na Educação Básica. In: MONTEIRO,A. M; GASPARELLO, A. M; MAGALHÃES, M. S. Ensino de História: sujeitos, saberes e práticas. Rio de Janeiro: Mauad X, 2007.

. (Org.). Ensinar e aprender História: formação, saberes e práticas educativas. São Paulo: Atomo \& Alínea, FAPEMIG, 2009. Vol. 1

FONSECA, T. N. L. História e Ensino de História. Belo Horizonte: Autêntica, 2009.

SCHMIDT, M. A. A formação do professor de história e o cotidiano da sala de aula. In: BITTENCOURT, C. (Org.) O saber histórico na sala de aula. São Paulo: Contexto, 2010.

SILVA, Marco. Sala de aula interativa: a educação presencial e à distância em sintonia com a era digital e coma cidadania. INTERCOM. XXIV Congresso Brasileiro de Comunicação. Campo Grande, setembro 2001. 